\title{
Body color polymorphism in nymphs and adults of a katydid, Conocephalus maculatus (Orthoptera: Tettigoniidae)
}

\author{
Ken-ichi Oda and Minoru Ishii \\ Entomological Laboratory, Graduate School of Agriculture and Biological Sciences, Osaka Prefecture University, Sakai, Osaka \\ 599-8531, Japan \\ (Received 18 October 2000; Accepted 9 March 2001)
}

\begin{abstract}
We observed color changes of the katydid, Conocephalus maculatus, from the hatchling to the adult stage under various rearing conditions using two populations in southern Osaka Prefecture. C. maculatus showed color polymorphism in the nymphal stage as well as in the adult stage: Although all the hatchlings were green irrespective of populations or conditions, the rate of green morph (G rate) decreased to $40-80 \%$ in the adult stage. Moreover, about $10 \%$ of individuals which had once turned brown returned to the green morph after one of the succeeding moults. The $\mathrm{G}$ rate of progenies between a green female and a green male tended to be higher than that between a brown female and a brown male throughout the nymphal stage, while environmental factors such as temperature, humidity and background color had no significant effect on nymphal color morph. The present results show that color-morph determination is controlled mainly by genetic factors and little affected by environmental factors in nymphs and adults of $C$. maculatus.
\end{abstract}

Key words: Conocephalus maculatus, color polymorphism, nymphal color change, reversible color change

\section{INTRODUCTION}

Green-brown polymorphism is common in orthopterans, although the factors that regulate body coloration differ from species to species (Okay, 1953; Rowell, 1971). In acridoid grasshoppers, much information has accumulated about the control of color polymorphism: Some grasshoppers change body coloration in response to environmental factors such as temperature, as in Oedaleus senegalensis (Colvin and Cooter, 1995), humidity and background color under low density, as in Locusta migratoria (Pener, 1991) and background color, as in Gastrimargus africanus (Rowell, 1970). The effects of endocrine factors on color polymorphism have been elucidated in Locusta migratoria (Tanaka and Pener, 1994; Tanaka, 2000a, b, c). Genetical control of body-color polymorphism, such as a striped or mottled wing, has been reviewed in Chortoicetes terminifera (Byrne, 1967) and Chorthippus brunneus (Gill, 1981). In Schistocerca gregaria, parental conditions such as a gregarious or solitarious phase affected the coloration of nymphs (Islam et al., 1994).

On the other hand, studies on color polymorphism in the suborder Ensifera are quite limited. Although high population density induces dark col- oration like the phase variation in some katydids (Owen, 1965; Robinson and Hartley, 1978; Ando and Hartley, 1982), the mechanism of color polymorphism in low population density is still unclear.

In the katydid, Conocephalus maculatus, the adult shows green-brown color polymorphism (Oda and Ishii, 1998). Conocephalus species including C. maculatus are predacious as well as herbivorous. They are known as insects of economic significance, being predators of both pineapple pests in the Pacific region (Pitkin, 1980) and rice pests in Malaysia (Ito et al., 1995). Although $C$. maculatus may be a harmful insect in agro-ecosystems of Japan (Ando, 1993), it serves as a predator of rice pests, as well (Nosato, 1983). It is of value to study color polymorphism in predacious and herbivorous orthopterans.

In a previous study (Oda and Ishii, 1998), we showed that the adult green-brown polymorphism in C. maculatus is partly controlled by genetic factors, and that environmental factors such as temperature, photoperiod, background color and humidity do not affect the rate of each morph. However, the details of the color change in the nymphal stage still remain unclear.

Thus, we observed the body color change of $C$. maculatus from the hatchling to the adult stage 
under different rearing conditions using two populations to elucidate the factors affecting color polymorphism in nymphs and adults.

\section{MATERIALS AND METHODS}

We selected two populations of C. maculatus derived from Osaka Prefecture University (OPU) in Sakai City and Murodo-cho (MRD) in Izumi City in southern Osaka Prefecture and compared color morph frequencies between them. We reared the $F_{1}$ hybrids of parent pairs of different color morphs under different temperature, humidity and background color conditions. We recorded the numbers of each color morph and dead individuals in each stage. Insect rearing, color morph recording and the combination of parent color morphs were done according to the methods described in Oda and Ishii (1998). Hatchlings were reared individually in 200- or 500-ml clear plastic cups. A lump of dog food, "Gaines Hearty" (Ajinomoto General Foods Co., Ltd.), was provided daily as the diet, and a sheet of soft paper was provided as an anchor for moulting. The inside of the cups was kept moist by spraying with water except in the low-humidity regime.

\section{RESULTS AND DISCUSSION}

\section{General features of nymphal color change}

All hatchlings of the two populations were green irrespective of the parent color morphs (Fig. 1). However, $20-70 \%$ of them turned yellow or yellowish-brown (referred to as "brown morph" below) after the 2nd stadium, and the rate of green morph ( $\mathrm{G}$ rate) decreased to $40-80 \%$ in the adult stage. The $\mathrm{G}$ rates were always higher throughout nymphal development in the $\mathrm{F}_{1}$ progenies $\mathrm{G} q \times \mathrm{G} \delta$ than in those $\mathrm{B}+\times \mathrm{B} \hat{\sigma}$, and the difference was significant at each stage from the 3 rd stadium to the adult stage in the MRD population (by $\chi^{2}$-test, $p<0.01, \mathrm{df}=1)$, and at the final stadium and the adult stage in the OPU population $(p<0.01$, $\mathrm{df}=1$ ). The results show that the body coloration of nymphs is strongly influenced by genetic factors like that of adults (Oda and Ishii, 1998).

It should be noted that about $10 \%$ of individuals which had once turned brown returned to the green morph after one of the succeeding moults (Fig. 2). This green-brown-green (GBG) type color change

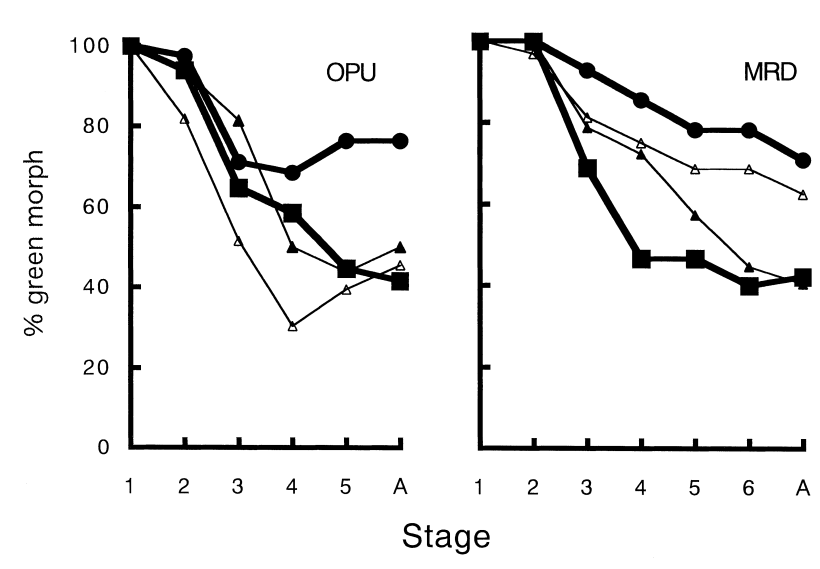

Fig. 1. Nymphal color change in the progeny of different parent pairs of color morphs in two populations (OPU and MRD) of Conocephalus maculatus in southern Osaka Prefecture. •: $\mathrm{F}_{1}$ hybrids $\mathrm{G}+\times \mathrm{G} \widehat{0}, \triangle: \mathrm{B} q \times \mathrm{G} \widehat{0}, \boldsymbol{\Delta}: \mathrm{G} q \times \mathrm{B} \widehat{0}$, $\mathrm{B}+\times \mathrm{B} \delta$.

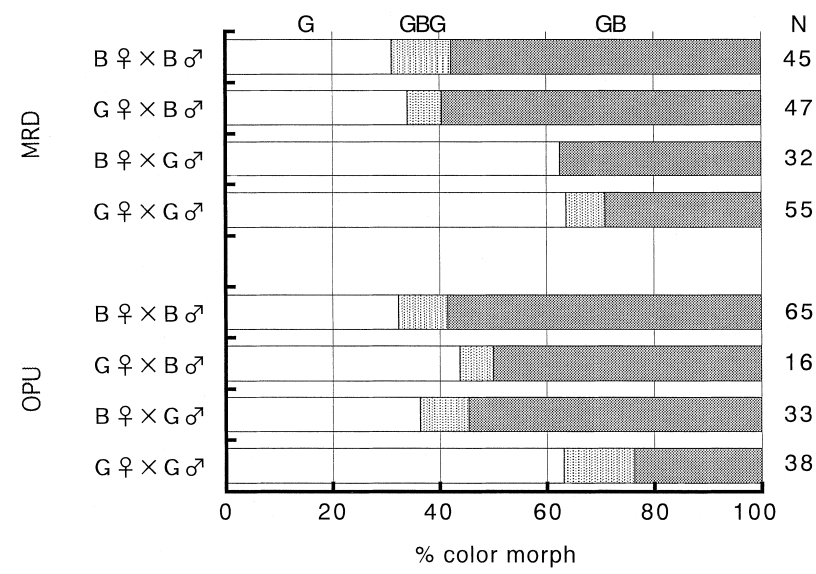

Fig. 2. Percentages of individuals remaining green $(G)$, turning brown (GB), and returning to the green morph after turning brown (GBG) during nymphal development at $25^{\circ} \mathrm{C}-16 \mathrm{~L}-8 \mathrm{D}$ in $\mathrm{F}_{1}$ hybrids of different parent color pairs in the OPU and MRD populations of $C$. maculatus.

occurred in both populations, and the change from brown to green was frequent in the last and penultimate stadia (see Fig. 1). Although the adult $G$ rates in $\mathrm{G}+\times \mathrm{G}{ }^{\star}$ were significantly higher than those of other parent combinations in color in both populations (OPU: $\chi^{2}=12.03, p<0.01, \mathrm{df}=1$; MRD: $\left.\chi^{2}=8.94, p<0.01, \mathrm{df}=1\right)$, the rates of GBG type (GBG rate) in $\mathrm{G}+\times \mathrm{G} 0^{\star}$ did not differ significantly from those in other combinations in the two populations (OPU: $p=0.308, \mathrm{df}=1$; MRD: $p=0.533$, $\mathrm{df}=1$ by Fisher's exact probability test). Thus the GBG rate seemed to be independent of the combination of parent color morph. Moreover, the GBG 
rates did not differ significantly between populations $\left(\chi^{2}=0.379, p>0.05, \mathrm{df}=1\right)$. Further investigation should be done to determine the biological significance of this reversible color change.

\section{Influence of environmental factors}

The survival rate varied under different conditions such as temperature and humidity in $C$. maculatus (Fig. 3). All nymphs died before the 4th stadium at a low temperature of $15^{\circ} \mathrm{C}$, and a high temperature of $30^{\circ} \mathrm{C}$ caused high mortality during the early nymphal stage. Low humidity also decreased the survival rate in all nymphal stages, and the rates of adult emergence differed significantly among the 3 humidity conditions $\left(\chi^{2}=7.054\right.$, $p<0.05, \mathrm{df}=2$ ).

On the other hand, environmental factors such as temperature, humidity and background color had

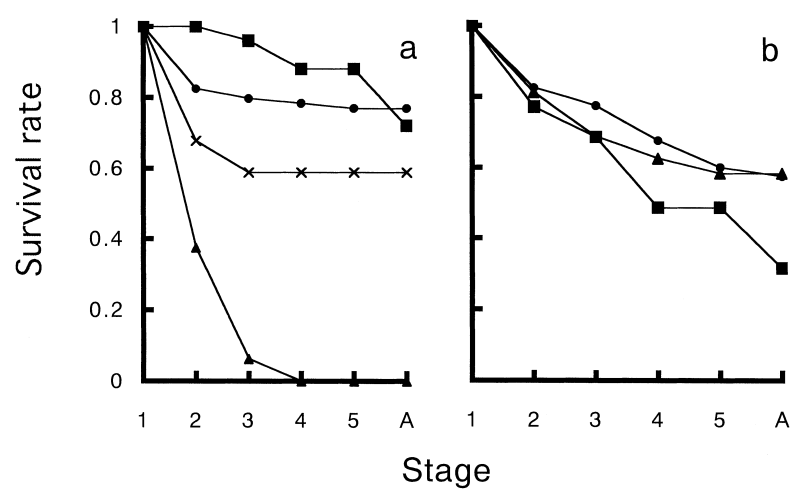

Fig. 3. The survivorship curve of C. maculatus under different temperature (a) and humidity (b) conditions. a: $\times: 30^{\circ} \mathrm{C}$, -: $25^{\circ} \mathrm{C}, \boldsymbol{\square}: 20^{\circ} \mathrm{C}, \mathbf{\Delta}: 15^{\circ} \mathrm{C}$, b: $\bullet$ : high humidity and moist diet, $\mathbf{\Delta}$ : high humidity and dry diet, $\mathbf{\square}$ : low humidity and moist diet. no significant effect on the $G$ rate in nymphs or adults (Fig. 4). No significant difference was observed in the adult $\mathrm{G}$ rate among the 3 humidity conditions (Fig. 4b: $\chi^{2}=1.489, p>0.05, \mathrm{df}=2$ ).

\section{Characteristics of nymphal color change in $C$. maculatus}

The nymphal color change pattern in C. maculatus may be characterized by three features: genetical control of the color morph, and late and reversible color changes. As described in Introduction, genetical and environmental effects on the color morph have been well studied in grasshoppers. Genetical color polymorphism has been reported in some katydids (Hancock, 1916; Rowell, 1971), however, environmental effects on the color morph are unknown in this family. As far as we know, this is the first report of reversible color change in grasshoppers and katydids. Further studies on color-morph determination in C. maculatus would contribute to a better understanding of the significance of color polymorphism in Orthoptera.

\section{ACKNOWLEDGEMENTS}

We would like to thank Dr. H. Tanaka of Osaka Prefectural Agricultural and Forestry Research Center for his helpful comments and discussion. Thanks are also due to Dr. T. Hirowatari, Mr. N. Hirai and other members of the Entomological Laboratory, Osaka Prefecture University for their encouragement and advice.

\section{REFERENCES}

Ando, Y. (1993) Outbreaks and ecology of rice grasshoppers. Shokubutsu bôeki 47: 311-314 (in Japanese).

Ando, Y. and J. C. Hartley (1982) Occurrence and biology of a long-winged form of Conocephalus discolor. Entomol. Exp. Appl. 32: 238-241.
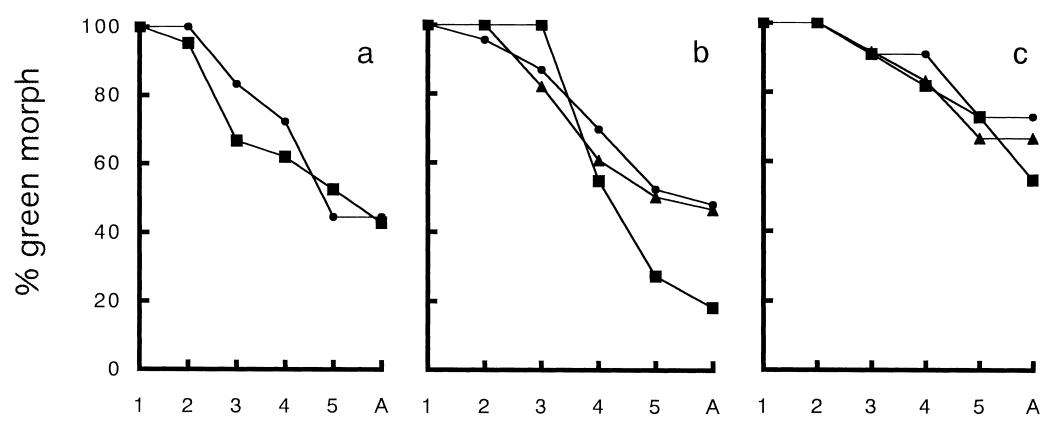

Stage

Fig. 4. Nymphal color change of C. maculatus under different temperatures (a), humidity (b) and background color (c) condi-

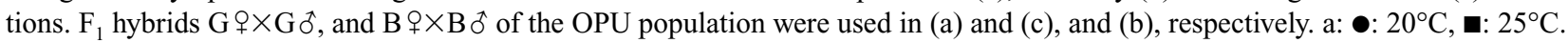
b: •: high humidity and moist diet, $\mathbf{\Lambda}$ : high humidity and dry diet, $\mathbf{\square}$ : low humidity and moist diet. c: $\bullet:$ white, $\mathbf{\Delta}:$ yellow, $\mathbf{\square}:$ blue. 
Byrne, O. W. (1967) Polymorphism in the Australian Acrididae. I. Inheritance of colour patterns in the plague locust, Chortoicetes terminifera. Heredity 22: 561-568.

Colvin, J. and R. J. Cooter (1995) Diapause induction and coloration in the Senegalese grasshopper, Oedaleus senegalensis. Physiol. Entomol. 20: 13-17.

Gill, P. (1981) The genetics of colour-patterns in the grasshopper Chorthippus brunneus. Biol. J. Linn. Soc. 16: $243-$ 259.

Hancock, J. L. (1916) Pink katydids and the inheritance of pink coloration. Entomol. News 27: 70-82.

Islam, M. S., P. Roessingh, S. J. Simpson and A. R. McCaffery (1994) Parental effects on the behaviour and colouration of nymphs of the desert locust Schistocerca gregaria. J. Insect Physiol. 40: 173-181.

Ito, K., H. N. Kin and C. P. Min (1995) Conocephalus longipennis (de Haan) (Orthoptera: Tettigoniidae): a suspected egg-predator of the rice bug in the Muda area, West Malaysia. Appl. Entomol. Zool. 30: 599-601.

Nosato, K. (1983) Natural enemies of the rice stem borer, Chilo suppressalis Walker (Lepidoptera: Pyralidae), in Kochi Prefecture. Gensei 43: 75-81 (in Japanese).

Oda, K. and M. Ishii (1998) Factors affecting adult color polymorphism in the meadow grasshopper, Conocephalus maculatus (Orthoptera: Tettigoniidae). Appl. Entomol. Zool. 33 : 455-460.

Okay, S. (1953) Formation of green pigment and colour changes in Orthoptera. Bull. Entomol. Res. 44: 299-315.

Owen, D. F. (1965) Swarming and polymorphism in the African edible grasshopper Homorocoryphus nitidulus
(Tettigonioidea, Conocephalidae). Acta Tropica 22: 5561.

Pener, M. P. (1991) Locust phase polymorphism and its endocrine relations. Adv. Insect Physiol. 21: 1-79.

Pitkin, L. M. (1980) A revision of the Pacific species of Conocephalus Thunberg (Orthoptera: Tettigoniidae). Bull. Br. Mus. Nat. Hist. 41: 315-355.

Robinson, D. J. and J. C. Hartley (1978) Laboratory studies of a tettigoniid (Insecta: Orthoptera) Ruspolia differens (Serville): colour polymorphism. J. Nat. Hist. 12: 81-86.

Rowell, C. H. F. (1970) Environmental control of coloration in an acridid, Gastrimargus africanus (Saussure). AntiLocust Bull. 47: 1-48.

Rowell, C. H. F. (1971) The variable coloration of the Acridoid grasshoppers. Adv. Insect Physiol. 8: 145-198.

Tanaka, S. (2000a) Induction of darkening by corazonins in several species of Orthoptera and their possible presence in ten insect orders. Appl. Entomol. Zool. 35: 509-517.

Tanaka, S. (2000b) The role of [His $\left.{ }^{7}\right]$-corazonin in the control of body-color polymorphism in the migratory locust, Locusta migratoria (Orthoptera: Acrididae). J. Insect Physiol. 46: 1169-1176.

Tanaka, S. (2000c) Hormonal control of body-color polymorphism in Locusta migratoria: interaction between [His ${ }^{7}$ corazonin and juvenile hormone. J. Insect Physiol. 46: $1535-1544$.

Tanaka, S. and M. P. Pener (1994) A neuropeptide controlling the dark pigmentation in color polymorphism of the migratory locust, Locusta migratoria. J. Insect Physiol. 40: 997-1005. 